\title{
Predictors of Asthma-related Quality of Life in a Large Cohort of Asthmatics: Towards a New Vison on Feno - A Cross-sectional Study in a Secondary Care Center
}

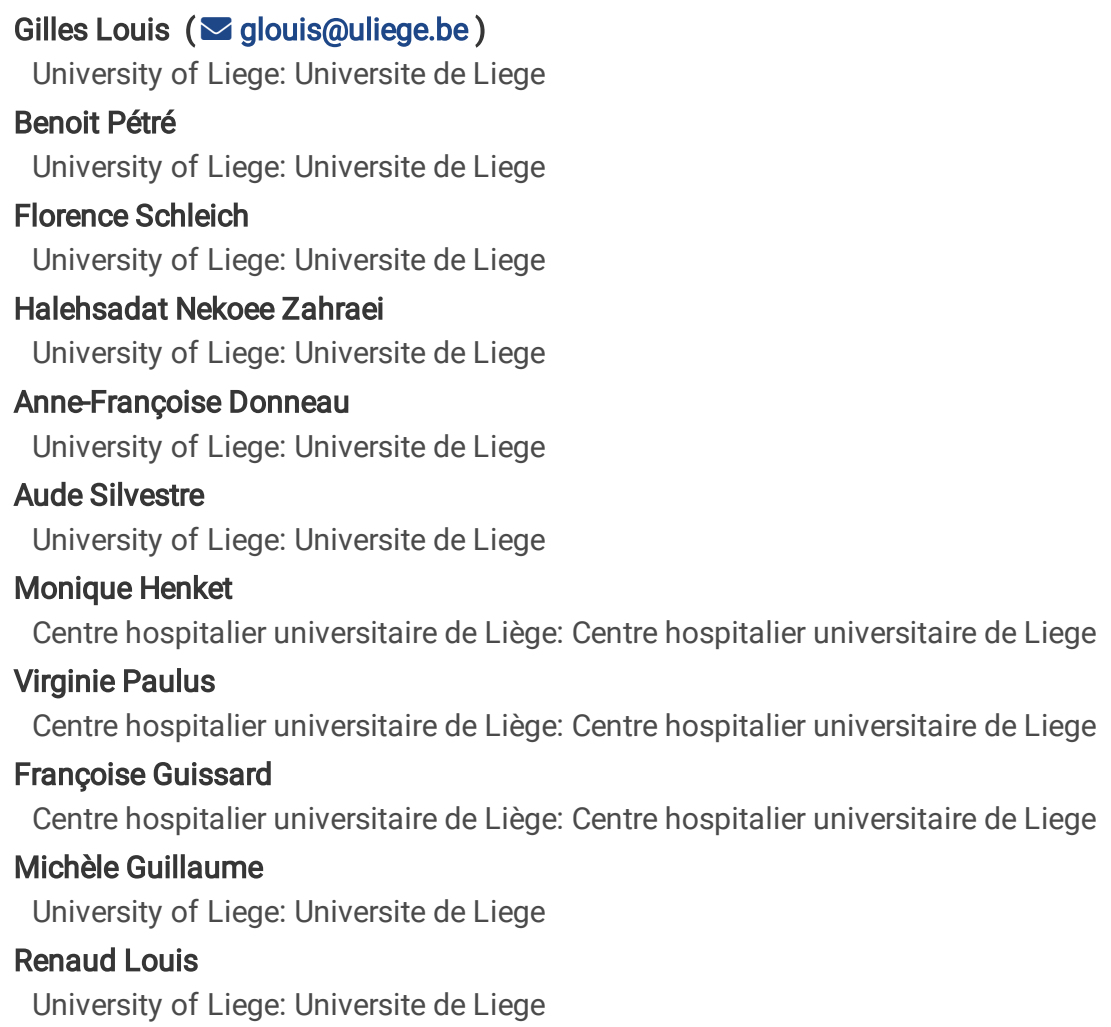

\section{Research}

Keywords: Asthma-related quality of life, Asthma control, FeNO

Posted Date: December 2nd, 2020

DOI: https://doi.org/10.21203/rs.3.rs-118181/v1

License: (c) (i) This work is licensed under a Creative Commons Attribution 4.0 International License. Read Full License 


\section{Abstract}

Background: In recent decades, measures of asthma-related quality of life have become important outcomes alongside clinical objective outcomes. In this study we sought to investigate the predictors of asthma-related quality of life in a large cohort of patients recruited from a secondary care center.

Methods: We conducted a cross-sectional study on asthmatics recruited from the asthma clinic of Chu Liège (Belgium). After carrying out a descriptive analysis highlighting the distribution of the mini asthma quality of life questionnaire (Mini-AQLQ) and its 4 dimensions (symptoms, activity limitation, emotional function and environmental stimuli), we performed a multiple regression analysis to identify the independent predictors of AQLQ.

Results: The median score (IQR) of global AQLQ was 4,53 (3,47-5,6), while the median score of symptom dimension, activity dimension, emotional dimension and environmental dimension were 4,2(3,2-5,4), 4,8 (3,3-6), 4,7 (3,3-6) et 4,7 (3,7-6) respectively. Multiple regression beta analysis showed that AQLQ and its 4 dimensions were primarily associated with asthma control test $(A C T)(p<0,0001$ in all instances). Female gender was associated with altered asthma quality of life for its activity and environmental dimension ( $p<0,05$ for both), while current smokers had a greater asthma quality of life in its environmental dimension $(p<0,0001)$. Receiving any asthma treatment was associated with impaired asthma quality of life in its emotional dimension. BMI was associated with impaired asthma quality of life in its activity dimension ( $p<0,0001$ ), while the reverse was found regarding FeNO $(p<0,0001)$.

Conclusion: Asthma control is the main predictor of asthma-related quality of life, but demographic factors like gender, smoking status and BMI may impact some dimensions of the asthma quality of life. FeNO is an independent predictor of the activity dimension of AQLQ and positively associated with it.

\section{Introduction}

Asthma is defined by the Global Initiative of Asthma (GINA) as a heterogeneous disease, usually characterized by chronic airway inflammation. It is diagnosed by the history of respiratory symptoms such as wheeze, shortness of breath, chest tightness and cough that vary over time and in intensity, together with variable expiratory airflow limitation $\left(^{1}\right)$.

This disease is a growing burden in terms of morbidity, health care costs and health-related quality of life (HRQL) $\left({ }^{2}\right)$. In recent decades, as a result of a paradigm shift towards patient-centered care, measures of health-related quality of life in asthma have become important outcomes alongside objective clinical outcomes $\left({ }^{3}\right)$. Therefore, international guidelines for the treatment of asthma have evolved to include the improvement of patients' health-related quality of life by maintaining long-term control of the disease, minimizing symptoms and improving physical, psychological and social function $\left({ }^{4}\right)$.

Unravelling the predictors of asthma-related quality of life is very important for the understanding of the disease and its treatment. Indeed, it provides meaningful information about the impact of the disease and treatment on patient's perceived health $\left(^{5}\right)$.

Many studies have already explored factors associated with asthma-related quality of life ( $\left.{ }^{6} 78910511\right)$. These works showed that the main factors were asthma control, gender, age, body mass index (BMI), education and socio-demographic parameters. Some studies have also shown weak univariate relationship between health-related quality of life and lung function as measured by forced expiratory volume in 1 second (FEV1) $\left({ }^{12} 13\right)$.

To our knowledge, no studies have explored the impact of the main inflammatory parameters of asthma (sputum eosinophils and neutrophils) on asthma-related quality of life, although airway inflammation is part of the asthma definition. In this study, we have assessed the predictors of asthma-related quality of life in a large cohort of asthmatics who were well characterized with respect to demographic features as well as their lung function and systemic and airway inflammatory parameters.

\section{Methods}

\section{Study design, setting and participants}

We conducted a cross-sectional study on patients with asthma recruited from the University Asthma Clinic of Liege (Belgium) between 2003 and 2019. In accordance with the GINA, the diagnosis of asthma was established by the presence of typical symptoms (wheezing, breathlessness, chest tightness and cough) combined with an increase in FEV1 of at least $12 \%$ of predicted value and $200 \mathrm{~mL}$ after inhalation of $400 \mu \mathrm{g}$ salbutamol and/or a provocative concentration of methacholine causing a fall in FEV1 of $20 \%$. From our database, we excluded patients who were under the age of 18 and those not clinically diagnosed with asthma. Then, among patients with asthma, we selected those who completed two patient-reported outcome measures (PROMs) in asthma, namely the asthma control test (ACT) $\left({ }^{14}\right)$ and the mini asthma quality of life

Page 2/16 
questionnaire (Mini-AQLQ) $\left({ }^{15}\right)$ on their first visit to the asthma clinic. Once these operations carried out, our sample size was 1301 asthmatics (Fig. 1).

\section{Variables}

All the variables used in this study were registered in the asthma clinic database during routine visits.

\section{Asthma-related quality of life (dependent variable)}

Asthma-related quality of life was measured using the Mini-Asthma Quality of Life Questionnaire (mini-AQLQ). This scientifically validated questionnaire has been translated into more than 20 languages and is intended for adults with asthma. It includes 15 items divided into 4 different dimensions: symptoms (5 items), activity limitation (4 items), emotional function (3 items) and environmental stimuli (3 items). The 15 items are scored 7-point Likert scales, and the overall score and the dimension scores are simple averages of the responses to the questions within them $\left({ }^{15}\right)$. A number of 7 indicates the highest score in terms of asthma-related quality of life. The minimum clinically important difference, understood as the smallest difference in a patient's perceived clinically important quality of life score $\left({ }^{16}\right)$, is 0.5 for Mini-AQLQ. Independent variables

We selected different variables from our database that might influence asthma-related quality of life. We have gathered them in two main groups, namely patient demographic characteristics and disease characteristics.

Patients demographic characteristics were age, gender, BMI, smoking status, onset of asthma and treatment. Smoking status was divided in three categories: non-smoker, ex-smoker and smoker. Treatment was divided in two categories: treated and non-treated. The treated one was composed of all patients who are currently taking any asthma medications including both maintenance and as needed medications.

Disease characteristics were asthma control, atopy, lung function and systemic and airway inflammation. Asthma control was assessed using the Asthma Control Test (ACT). It consists of 5 questions related to symptomatology and activity limitation. Each question contains 5 items, each with a score ranging from 1 to 5 . Studies have established the cutoff scores for controlled asthma (ACT $\geq 20$ ), not well-controlled asthma $(\mathrm{ACT} \leq 19)$ and uncontrolled asthma $(\mathrm{ACT} \leq 15)\left({ }^{14} 17\right)$. Atopy was defined by the presence of one positive $\mathrm{lgE}(>0,35 \mathrm{kU} / \mathrm{L})$ to one or more common aeroallergen (grass pollen, tree pollen, cat, dog, molds, and house dust mite). Lung function testing was performed by spirometry (spirobank; MIR, Rome, Italy). Inflammatory parameters included Fractional exhaled nitric oxide (FENO), sputum cell counts, blood cell counts and systemic markers. FENO was measured at a flow rate of $50 \mathrm{~mL} / \mathrm{s}$ (NIOX; Aerocrine, Solna, Sweden). Sputum induction and processing were performed as previously described $\left({ }^{18}\right)$. The success rate of sputum induction and analysis in our asthma clinic was $78 \%(1013$ of 1301 patients with asthma). C reactive protein (CRP), fibrinogen, blood eosinophils and neutrophils counts were carried out by routine laboratory of the University Hospital of Liege.

\section{Statistical analysis}

Assessment of the normality of the distribution of the quantitative data was investigated numerically by comparing mean and median, graphically using histogram and quantile-quantile plot. Shapiro-Wilk normality test was applied to complete this assessment. Quantitative variables were summarized accordingly using median and interquartile range (P25 - P75), while count and percentage were calculated for qualitative variables. The number and percentage of missing values were also reported. The associations between the quantitative variables and AQLQ and subscales (Symptom dimension, Activity dimension, Emotional dimension, Environmental dimension) were first determined using the Spearman correlation coefficient. We further analyzed the determinants of AQLQ and its four subscales by multiple regression analysis. Based on the skewed and bounded, i.e. values restricted to the interval between values 1 and 7 , structure of the outcome variable, the beta regression model was considered. For that purpose, the values of the outcomes were rescaled to the unit interval using the following transformation $\mathrm{y}^{\wedge \star}=$ $([\mathrm{y}(\mathrm{n}-1)+0.5]) / \mathrm{n}$ where $\mathrm{n}$ is the sample size $\left({ }^{19}\right)$. In this study, as several models were fitted, the best model was selected by the Akaike information criterion (AIC) with a lower AIC value indicating a better fit. All statistical modeling was carried out using the statistical software R in the level of significance 0.05 .

\section{Ethics}

Study was approved by the CHU Liège ethics committee. Signed informed consent was obtained from patients as soon as they entered the asthma clinic. They agreed that their clinical data and the health outcomes they reported in the routine setting would be used for the purposes of research.

\section{Results}

\section{Characteristics of the study population}


The demographic characteristics of the study population are presented in Table 1. The proportion of female was dominant (60\%). Never smokers represented $54 \%$ of our population while ex-smokers and current smokers accounted for $26 \%$ and $20 \%$ of the population, respectively. Atopic trait was found in a slight majority of the patient (54\%). Median body mass index was 26 with an interquartile range from $23-30$ meaning that $25 \%$ of our population were obese. The vast majority of asthma patients were receiving a medical treatment for asthma at the time of the visit (87\%).

Table 1

Demographic characteristics

\begin{tabular}{|c|c|c|c|}
\hline \multicolumn{2}{|l|}{ Variable } & Median (IQR) / & Percentage (Number) of missing value \\
\hline & & Percentage(n) & \\
\hline \multicolumn{2}{|l|}{ Age (Year) } & $51(37-62)$ & $0 \%(0)$ \\
\hline \multicolumn{2}{|l|}{ Gender (Male) } & $40 \%(523)$ & $0 \%(0)$ \\
\hline \multirow[t]{3}{*}{ Smoking Status } & Non-Smoker & $54 \%(698)$ & \multirow[t]{3}{*}{$0.69 \%(9)$} \\
\hline & Ex-Smoker & $26 \%(340)$ & \\
\hline & Smoker & $20 \%(254)$ & \\
\hline \multicolumn{2}{|c|}{ Onset of asthma (Year) } & $22(10-50)$ & $21 \%(270)$ \\
\hline \multicolumn{2}{|l|}{ BMI (kg/m2) } & $26(23-30)$ & $0.08 \%(1)$ \\
\hline \multicolumn{2}{|l|}{ Atopy (Yes) } & $54 \%(648)$ & $9 \%(113)$ \\
\hline \multicolumn{2}{|c|}{ Any asthma treatment (Yes) } & $87 \%(1129)$ & $0.08 \%(1)$ \\
\hline
\end{tabular}

Median AQLQ score was 4,53 with a non-gaussian distribution as show in Fig. 2. Likewise, the distribution of the different dimensions of the AQLQ was non-parametric as shown in Fig. 3. Asthma control, lung function and inflammatory characteristics are presented in Table 2. As for asthma control median ACT was 15 with interquartile range from 11-20 indicating that patients with well-controlled asthma represented $25 \%$ of the cohort $(\geq 20)$.

Table 2

Asthma control, lung function and inflammatory characteristics

\begin{tabular}{|lll|}
\hline Variable & Median (IQR) / & Percentage (Number) of missing value \\
& Percentage(frequency) & \\
\hline ACT & $15(11.0-20.0)$ & $0 \%(0)$ \\
\hline FEV1 pre (\% pred.) & $86(73.0-99.0)$ & $0.23 \%(3)$ \\
\hline FEV1 post (\% pred.) & $91(78.5-104.0)$ & $0.61 \%(8)$ \\
\hline FVC pre (\% pred.) & $95(82.0-106.0)$ & $0.15 \%(2)$ \\
\hline FVC post (\% pred.) & $97(85.0-108.0)$ & $0.69 \%(9)$ \\
\hline FEV1/FVC pre (\%) & $76(69.0-82.0)$ & $0.15 \%(2)$ \\
\hline FEV1/FVC post (\%) & $79(72.0-84.0)$ & $0.61 \%(8)$ \\
\hline FENO (ppb) & $22(13.0-42.0)$ & $2.07 \%(27)$ \\
\hline Sputum neutrophils $\left(10^{3} / \mathrm{g}\right)$ & $764(272-2662.5)$ & $22.14 \%(288)$ \\
\hline Sputum eosinophils $\left(10^{3} / \mathrm{g}\right)$ & $27(1.12-192.66)$ & $22.14 \%(288)$ \\
\hline Blood neutrophils $(1 / \mu \mathrm{L})$ & $3966(3077-5254)$ & $2.0 \%(26)$ \\
\hline Blood eosinophils $(1 / \mu \mathrm{L})$ & $171(98.0-298.0)$ & $2.0 \%(26)$ \\
\hline Total serum IgE (KU/L) & $98(30.0-291.0)$ & $4.15 \%(54)$ \\
\hline Fibrinogen (g/l) & $3.25(2.75-3.78)$ & $5.69 \%(74)$ \\
\hline CRP (mg/I) & $2.15(0.9-5.01)$ & $4.84 \%(63)$ \\
\hline IQR: Interquartile range; $\mathrm{n}$ ( number of patients & \\
\hline
\end{tabular}

Page $4 / 16$ 


\section{Correlation between asthma-related quality of life and demographic and disease characteristics}

Correlation between demographic and clinical parameters and AQLQ variable and its four subscales are reported in Table 3. ACT was strongly positively correlated with global AQLQ score $(r=0.81)$ and its 4 subscales. To a lesser extent, FEV1 pre (\%), FEV1 post (\%), FVC pre (\%) and FVC post (\%) were positively correlated with global AQLQ score and its four subscales. BMI was weakly and inversely correlated with global AQLQ and its subscales of symptoms and activity. As for inflammatory parameters, they all inversely correlated with global AQLQ apart from FENO and total serum IgE which displayed no correlation. However, these two inflammatory parameters showed a significant relationship with two subscales. Indeed, FENO was positively associated with the activity dimension and total serum IgE was negatively associated with the emotional dimension. Among the several inflammatory parameters, blood neutrophils provided the strongest relationships. 
Table 3

Correlation between asthma-related quality of life (AQLQ) and demographic and disease characteristics

\begin{tabular}{|c|c|c|c|c|c|c|c|c|c|c|}
\hline & \multicolumn{2}{|c|}{ Global AQLQ } & \multicolumn{2}{|c|}{ Symptom dimension } & \multicolumn{2}{|c|}{ Activity dimension } & \multicolumn{2}{|c|}{ Emotional dimension } & \multicolumn{2}{|c|}{$\begin{array}{l}\text { Environmental } \\
\text { dimension }\end{array}$} \\
\hline & Correlation & $\begin{array}{l}\text { P- } \\
\text { Value }\end{array}$ & Correlation & $\begin{array}{l}\text { P- } \\
\text { Value }\end{array}$ & Correlation & $\begin{array}{l}\mathrm{P} \text { - } \\
\text { Value }\end{array}$ & Correlation & $\begin{array}{l}\text { P- } \\
\text { Value }\end{array}$ & Correlation & $\begin{array}{l}\text { P- } \\
\text { Value }\end{array}$ \\
\hline ACT & 0.81 & $\begin{array}{l}<.0001 \\
0\end{array}$ & 0.79 & $<.0001$ & 0.76 & $<.0001$ & 0.71 & $<.0001$ & 0.48 & $\begin{array}{l}< \\
0.0001\end{array}$ \\
\hline Age (Year) & -0.01 & 0.84 & 0.04 & 0.12 & -0.12 & $<.0001$ & 0.01 & 0.64 & 0.04 & 0.11 \\
\hline $\begin{array}{l}\text { Onset of asthma } \\
\text { (Year) }\end{array}$ & 0.06 & 0.04 & 0.04 & 0.26 & -0.03 & 0.31 & 0.10 & 0.001 & 0.14 & $\begin{array}{l}< \\
0.0001\end{array}$ \\
\hline BMI (kg/m2) & -0.12 & $<.0001$ & -0.10 & 0.0003 & -0.21 & $\begin{array}{l}<.0001 \\
0.00\end{array}$ & -0.07 & 0.009 & -0.03 & 0.26 \\
\hline $\begin{array}{l}\text { FEV1 pre (\% } \\
\text { pred.) }\end{array}$ & 0.31 & $<.0001$ & 0.26 & $<.0001$ & 0.34 & $<.0001$ & 0.29 & $<.0001$ & 0.15 & $\begin{array}{l}< \\
0.0001\end{array}$ \\
\hline $\begin{array}{l}\text { FEV1 post (\% } \\
\text { pred.) }\end{array}$ & 0.31 & $<.0001$ & 0.26 & $<.0001$ & 0.34 & $\begin{array}{l}< \\
0.0001\end{array}$ & 0.28 & $<.0001$ & 0.15 & $\begin{array}{l}< \\
0.0001\end{array}$ \\
\hline FVC pre (\% pred.) & 0.28 & $<.0001$ & 0.22 & $\begin{array}{l}<.0001 \\
0.00\end{array}$ & 0.34 & $<.0001$ & 0.23 & $<.0001$ & 0.13 & $<.0001$ \\
\hline $\begin{array}{l}\text { FVC post (\% } \\
\text { pred.) }\end{array}$ & 0.24 & $<.0001$ & 0.18 & $<.0001$ & 0.30 & $\begin{array}{l}<.0001 \\
\end{array}$ & 0.19 & $<.0001$ & 0.12 & $\begin{array}{l}< \\
0.0001\end{array}$ \\
\hline $\begin{array}{l}\text { FEV1/FVC pre } \\
\text { (\%) }\end{array}$ & 0.12 & $<.0001$ & 0.10 & $<.0001$ & 0.11 & $<.0001$ & 0.16 & $<.0001$ & 0.02 & 0.51 \\
\hline $\begin{array}{l}\text { FEV1/FVC post } \\
(\%)\end{array}$ & 0.14 & $\begin{array}{l}<.0001 \\
0.0\end{array}$ & 0.13 & $\begin{array}{l}<.0001 \\
0\end{array}$ & 0.15 & $\begin{array}{l}<.0001 \\
0.00\end{array}$ & 0.17 & $<.0001$ & 0.03 & 0.36 \\
\hline FENO (ppb) & 0.04 & 0.13 & 0.03 & 0.25 & 0.09 & 0.0007 & -0.02 & 0.47 & -0.01 & 0.84 \\
\hline Fibrinogen (g/l) & -0.14 & $<.0001$ & -0.12 & $\begin{array}{l}< \\
0.0001\end{array}$ & -0.19 & $<.0001$ & -0.08 & 0.003 & -0.06 & 0.04 \\
\hline CRP (mg/l) & -0.10 & 0.0004 & -0.11 & $<.0001$ & -0.14 & $<.0001$ & -0.04 & 0.17 & -0.03 & 0.22 \\
\hline $\begin{array}{l}\text { Total serum lgE } \\
(\mathrm{KU} / \mathrm{L})\end{array}$ & 0.00 & 0.98 & 0.01 & 0.65 & 0.03 & 0.24 & -0.08 & 0.006 & 0.00 & 0.93 \\
\hline $\begin{array}{l}\text { Sputum } \\
\text { neutrophils } \\
\left(10^{3} / \mathrm{g}\right)\end{array}$ & -0.06 & 0.04 & -0.06 & 0.07 & -0.08 & 0.01 & -0.03 & 0.37 & -0.05 & 0.14 \\
\hline $\begin{array}{l}\text { Sputum } \\
\text { eosinophils } \\
\left(10^{3} / \mathrm{g}\right)\end{array}$ & -0.09 & 0.006 & -0.09 & 0.004 & -0.06 & 0.08 & -0.10 & 0.002 & -0.06 & 0.05 \\
\hline $\begin{array}{l}\text { Blood } \\
\text { neutrophils (1/ } \\
\mu \mathrm{L})\end{array}$ & -0.20 & $\begin{array}{l}< \\
0.0001\end{array}$ & -0.19 & $\begin{array}{l}< \\
0.0001\end{array}$ & -0.22 & $\begin{array}{l}< \\
0.0001\end{array}$ & -0.17 & $\begin{array}{l}< \\
0.0001\end{array}$ & -0.07 & 0.01 \\
\hline $\begin{array}{l}\text { Blood } \\
\text { eosinophils ( } 1 / \\
\mu L)\end{array}$ & -0.08 & 0.004 & -0.08 & 0.007 & -0.07 & 0.01 & -0.10 & $<.0001$ & -0.04 & 0.12 \\
\hline
\end{tabular}

\section{Multivariate Beta regression}

The results of multivariate beta regression analysis are presented in Table 4. ACT was the only determinant displaying significant association with global AQLQ $(p<0.0001)$ and its four subscales $(p<0.0001)$. CRP showed a significant association $(p=0.04)$ with global AQLQ but it did not hold true for any subscale. None of the other independent variables was associated with global AQLQ. Gender had an influence on activity and environmental domains so that female had lower asthma-related quality of life in its activity $(p=0.037)$ and environmental $(p=0.016)$ dimension than male. Likewise, treatment had significant association with the emotional subscale. That is, treated patients had lower asthmarelated quality of life in its emotional dimension than untreated patients $(p=0.018)$. Smoking patients had higher asthma-related quality of life in 
its environmental dimension than non-smoking patients $(p<0.0001)$. BMI was inversely associated with activity subscale $(p<0.0001)$ while FENO (ppb) was positively associated with this subscale $(p<0.0001)$ (Fig. 4).

Table 4

Multivariate Beta regression results for asthma-related quality of life and its 4 dimensions

\begin{tabular}{|c|c|c|c|c|c|c|c|c|c|c|c|}
\hline & & \multicolumn{2}{|c|}{ Global AQLQ } & \multicolumn{2}{|c|}{ Symptom dimension } & \multicolumn{2}{|c|}{ Activity dimension } & \multicolumn{2}{|l|}{$\begin{array}{l}\text { Emotional } \\
\text { dimension }\end{array}$} & \multicolumn{2}{|c|}{$\begin{array}{l}\text { Environmental } \\
\text { dimension }\end{array}$} \\
\hline & & Estimate & $\begin{array}{l}\text { P- } \\
\text { Value }\end{array}$ & Estimate & $\begin{array}{l}\text { P- } \\
\text { Value }\end{array}$ & Estimate & $\begin{array}{l}\text { P- } \\
\text { Value }\end{array}$ & Estimate & $\begin{array}{l}\text { P- } \\
\text { Value }\end{array}$ & Estimate & $\begin{array}{l}\text { P- } \\
\text { Value }\end{array}$ \\
\hline \multicolumn{2}{|l|}{ ACT } & $0.139^{\star *}$ & $\begin{array}{l}< \\
0.0001\end{array}$ & $0.149^{\star *}$ & $\begin{array}{l}< \\
0.0001\end{array}$ & $0.158^{\star *}$ & $\begin{array}{l}< \\
0.0001\end{array}$ & $0.148^{\star *}$ & $\begin{array}{l}<.0001 \\
0.00\end{array}$ & $0.090^{\star \star}$ & $\begin{array}{l}< \\
0.0001\end{array}$ \\
\hline \multicolumn{2}{|c|}{ Gender (Male) } & 0.065 & 0.17 & 0.005 & 0.921 & $0.132^{\star}$ & 0.037 & -0.069 & 0.368 & $0.195^{\star}$ & 0.016 \\
\hline \multicolumn{2}{|l|}{ Age (Year) } & -0.00004 & 0.983 & 0.001 & 0.648 & -0.003 & 0.25 & 0.0003 & 0.926 & -0.0004 & 0.908 \\
\hline \multirow[t]{2}{*}{$\begin{array}{l}\text { Smoking } \\
\text { Status }\end{array}$} & $\begin{array}{l}\text { Ex- } \\
\text { smokers }\end{array}$ & -0.041 & 0.457 & -0.027 & 0.666 & -0.033 & 0.656 & -0.055 & 0.545 & -0.053 & 0.572 \\
\hline & $\begin{array}{l}\text { Current } \\
\text { smokers }\end{array}$ & 0.105 & 0.082 & -0.088 & 0.194 & 0.095 & 0.231 & 0.139 & 0.156 & $0.435^{* *}$ & $<.0001$ \\
\hline \multicolumn{2}{|c|}{ Atopy (Yes) } & 0.034 & 0.519 & 0.105 & 0.077 & 0.064 & 0.358 & -0.013 & 0.876 & -0.031 & 0.731 \\
\hline \multicolumn{2}{|c|}{$\begin{array}{l}\text { Onset of asthma } \\
\text { (Year) }\end{array}$} & 0.0003 & 0.835 & -0.0004 & 0.801 & -0.003 & 0.172 & 0.0008 & 0.723 & 0.004 & 0.093 \\
\hline \multicolumn{2}{|c|}{ Treatment (Yes) } & -0.103 & 0.217 & -0.008 & 0.928 & -0.074 & 0.506 & $-0.313^{*}$ & 0.018 & -0.172 & 0.209 \\
\hline \multicolumn{2}{|c|}{ Fibrinogen (g/l) } & -0.017 & 0.591 & -0.007 & 0.848 & -0.035 & 0.411 & -0.019 & 0.703 & 0.016 & 0.768 \\
\hline \multicolumn{2}{|c|}{ CRP (mg/l) } & $0.005^{\star}$ & 0.048 & 0.003 & 0.242 & 0.003 & 0.352 & 0.007 & 0.063 & 0.003 & 0.515 \\
\hline \multicolumn{2}{|c|}{ Total IgE (KU/L) } & 0.000008 & 0.801 & -0.000003 & 0.923 & 0.00004 & 0.306 & -0.00004 & 0.476 & -0.00004 & 0.488 \\
\hline \multicolumn{2}{|c|}{ FEV1 pre (\%) } & 0.0003 & 0.944 & -0.0056 & 0.296 & -0.003 & 0.685 & 0.011 & 0.134 & -0.003 & 0.687 \\
\hline \multicolumn{2}{|c|}{ FEV1 post (\%) } & 0.005 & 0.333 & 0.0101 & 0.067 & 0.009 & 0.149 & -0.0006 & 0.935 & 0.0006 & 0.941 \\
\hline \multicolumn{2}{|c|}{ FVC pre (\%) } & 0.003 & 0.632 & 0.008 & 0.184 & 0.009 & 0.194 & -0.0007 & 0.409 & 0.0013 & 0.884 \\
\hline \multicolumn{2}{|c|}{ FVC post (\%) } & -0.003 & 0.609 & -0.0098 & 0.095 & -0.007 & 0.303 & 0.003 & 0.700 & 0.0026 & 0.768 \\
\hline \multicolumn{2}{|c|}{$\begin{array}{l}\text { Sputum neutrophils } \\
\left(10^{3} / \mathrm{g}\right)\end{array}$} & -0.000003 & 0.321 & -0.000007 & 0.051 & -0.000005 & 0.198 & 0.000001 & 0.764 & -0.000002 & 0.699 \\
\hline \multicolumn{2}{|c|}{$\begin{array}{l}\text { Sputum eosinophils } \\
\left(10^{3} / \mathrm{g}\right)\end{array}$} & 0.000007 & 0.501 & 0.00001 & 0.259 & 0.000003 & 0.829 & 0.00002 & 0.229 & 0.000004 & 0.837 \\
\hline \multicolumn{2}{|c|}{$\begin{array}{l}\text { Blood eosinophils } \\
(\mu L)\end{array}$} & 0.000017 & 0.714 & -0.00004 & 0.374 & -0.000004 & 0.948 & 0.00009 & 0.237 & 0.000067 & 0.407 \\
\hline \multicolumn{2}{|c|}{$\begin{array}{l}\text { Blood neutrophils } \\
(\mu \mathrm{L})\end{array}$} & -0.000003 & 0.482 & 0.0000001 & 0.992 & 0.00002 & 0.766 & -0.000009 & 0.282 & -0.00001 & 0.221 \\
\hline \multicolumn{2}{|c|}{ FENO (ppb) } & 0.00089 & 0.133 & -0.00039 & 0.559 & $0.003^{\star \star}$ & $\begin{array}{l}< \\
0.0001\end{array}$ & 0.000098 & 0.918 & 0.00033 & 0.739 \\
\hline \multicolumn{2}{|c|}{ BMI (kg/m2) } & -0.005 & 0.344 & -0.0027 & 0.618 & $-0.022^{\star *}$ & $<.0001$ & 0.0059 & 0.439 & 0.0047 & 0.562 \\
\hline \multicolumn{2}{|c|}{$\begin{array}{l}\text { Akaike information } \\
\text { criterion (AIC) }\end{array}$} & \multicolumn{2}{|l|}{-915.754} & \multicolumn{2}{|l|}{-751.59} & \multicolumn{2}{|l|}{-680.16} & \multicolumn{2}{|l|}{-441.88} & \multicolumn{2}{|l|}{-250.898} \\
\hline
\end{tabular}

\section{Discussion}

In our large cross-sectional study, we identified several predictors of asthma-related quality of life and/or its 4 dimensions as measured by AQLQ. First, our results show that ACT is the factor most significantly associated with global AQLQ and its 4 dimensions (symptoms, activity limitation, emotional function and environmental stimuli). Second, our results show that some demographic characteristics including gender, BMI, smoking status and treatment are predictors of certain dimensions of asthma-related quality of life. Third, while cellular inflammatory and lung function 
parameters are correlated to the global AQLQ, it does not hold true anymore after multivariate analysis. Finally, and this is the most original finding of our study, FENO appears to be positively associated with the activity dimension.

The level of asthma control assessed by ACT was identified as the major predictor of asthma-related quality of life as measured by AQLQ. Indeed, it was the only factor strongly associated with global AQLQ and all AQLQ dimensions. These results are in line with previous studies indicating that asthma control had a strong influence on health-related quality of life $\left({ }^{8} 9202122723\right)$. Chen et al $\left({ }^{8}\right)$, using a multivariate analysis in a large cohort, found an inverse relationship between asthma control (measured by Asthma Therapy Assessment Questionnaire, ATAQ) and both asthma specific health-related quality of life, measured by Mini-AQLQ, and generic health-related quality of life, measured by EuroQol 5-D. Likewise, Pereira et al (2011) $\left({ }^{20}\right)$, reported an inverse relationship between asthma control (measured by ACT) and asthma specific healthrelated quality of life, measured by Saint Georges's Respiratory Questionnaire (SGRQ) but this study investigated a limited number of patients. The strong relationship between ACT and AQLQ in our study $(r s=0,81)$ can be explained, in part, by the fact that AQLQ has two dimensions (activity limitation and symptoms) that are also found in ACT. The overlap of common domains is likely to strengthen the relationship between the two questionnaires $\left({ }^{22}\right)$.

In our study, even if there was no difference in global AQLQ, women reported poorer asthma-related quality of life in the dimensions of activity limitation and environmental stimuli. Our finding of a significant association between gender and the AQLQ dimensions of activity limitation and environmental stimuli is perfectly in line with study conducted by Naleway et al.( $\left.{ }^{24}\right)$. Other studies reported that women with asthma experienced a lower health-related quality of life $\left(\begin{array}{lll}25 & 26 & 10\end{array}\right)$. Some authors $\left({ }^{25} 27\right)$ consider that the relationship between gender and asthma-related quality of life is depending on the higher prevalence of anxiety and depression among women compared to men. In our study we did not observe any gender differences in the emotional dimension of the AQLQ, but we recognize that this dimension does not take into account the anxiety and depression.

A previous study reported that asthmatic smokers had a lower generic health-related quality of life $\left({ }^{10}\right)$. We could not confirm this finding when focusing on the asthma-related quality of life by itself. On the contrary, in the present study, smoking patients had a higher asthma-related quality of life in its environmental dimension than non-smoking patients. It seems surprising, but it can be explained by the composition and formulation of the AQLQ's environmental questions. Indeed, among the 3 questions that make up the AQLQ's environmental domain, one asks whether the patient has been bothered by cigarette smoke. It is very likely that most smokers responded "rarely or never" to this question. Moreover, it is worth noting that the relationship between smoking and asthma-related quality of life is different from the one between smoking and asthma control, where smoking has a clear detrimental effect on the level of control $\left({ }^{28}\right)$. This illustrates that although being strongly related asthma control and asthma quality of life reflect different dimensions of the disease.

Obesity is a major comorbidity in asthma affecting up to $25-50 \%$ of severe asthmatics according to the countries $\left({ }^{29}\right)$. In our study, BMI was negatively associated with AQLQ activity limitation dimension. This means that the higher the BMI of an asthma patient, the poorer his or her asthma-related quality of life in the activity dimension. This finding is in line with another study carried out by Lavoie et al. $\left({ }^{30}\right)$ and is well understandable given the burden obesity places in everyday life movement. It also demonstrates the importance of taking co-morbidities into account when assessing the quality of life of asthmatics.

In our study neither atopy, which was present in more than half of the asthma cohort, nor total serum IgE are associated with global asthma quality of life and any of its subscales. Thus we cannot confirm that non atopic asthma may lead to greater alteration of asthma quality of life as shown in a previous study $\left.{ }^{31}\right)$. In the latter study more than $70 \%$ of the cohort were atopic patients with younger age and less severe disease with only half treated with ICS and average FEV1 value above $90 \%$ predicted. In our cohort atopic patients had baseline FEV 1 at $86 \%$ and $62 \%$ of them were treated with ICS/LABA (data not shown). Therefore, we believe that our population of atopic asthmatics was more severe than the population of Ek et al $\left({ }^{31}\right)$. Our data support that atopy is a prominent trait associated with asthma, however, not determinant to either deteriorate or improve quality of life.

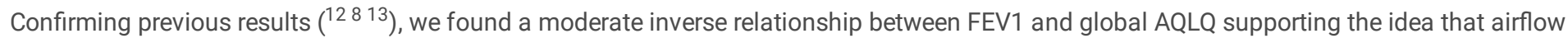
limitation results in impaired quality of life. However, this relationship did not hold true after multiple regression analysis indicating that airflow limitation is not an independent predictor of asthma related quality of life. Therefore, it is presumable that airflow limitation relates to quality of life through impairing asthma control since it has shown that fluctuation in airway caliber was an independent factor associated with asthma control $\left({ }^{32} 28\right)$.

Airway inflammation is an essential component of asthma. To our knowledge there has not been studies looking at the direct relationship between asthma-related quality of life and airway or systemic inflammation. Thus, one originality of our study was to explore the link between asthma-related quality of life and airway inflammation. The magnitude of neutrophilic and eosinophilic inflammation both at systemic and airway level inversely correlates with overall AQLQ score. In other words, the higher the eosinophils and/or neutrophils in the sputum and in the blood, the poorer the asthma-related quality of life. Nevertheless, the relationship between these inflammatory parameters and asthma-related 
quality of life disappeared in the multivariate model. As it is the case for FEV1, it suggests that the relationship is depending on the level of asthma control, as it has been previously shown that sputum eosinophils are independent determinants of the fluctuation in asthma control both in cross-sectional and longitudinal studies $(3332$ 28).

Finally, our multivariate analysis yielded a surprising and interesting result regarding FENO. It showed that FENO was positively associated with the activity dimension of asthma-related quality of life. High FENO has been traditionally seen as a bad outcome reflecting intense eosinophilic inflammation $\left({ }^{34}\right)$. In addition, Roberts et al. $\left({ }^{35}\right)$, focusing on allergic asthmatic teenagers, demonstrated that quality of life deteriorates when FENO increases as a consequence of pollen allergen exposure. In severe allergic asthmatics Caminati et al. $\left({ }^{36}\right)$, showed that AQLQ scores were lower in patients with FENO $\geq 30 \mathrm{ppb}$ than in patients with FENO $<30 \mathrm{ppb}$. None of these studies had used multiple regression analysis and FENO may be influenced by other factors susceptible to impact its effect on AQLQ in a univariate analysis such as airway eosinophilia.

Therefore, we believe that our statistical methods better reflect the true association between FENO and quality of life. The reason why FENO may positively affect the activity dimension of the quality of life remains to be investigated but it is worth noting that NO is a recognized mediator of vasodilation in the body $\left({ }^{37}\right)$, which is a physiological process of utmost importance in physical activity. While FENO is usually considered to be the consequence of activation of inducible NO synthase as a result of local inflammation $\left({ }^{38}\right)$, we cannot exclude that part of FENO actually reflects an inherited propensity of the body to synthetize NO. In any case our finding invites asthma specialists to rethink the way they conceive FENO, but also with this in mind, to rethink the way they manage an asthma patient with a high level of FENO. In this regard it is of interest to mention that anti-IL-5 may dramatically improve asthma-related quality of life without changing FENO levels which may remain very high in some patients $\left({ }^{39} 40\right)$.

The strength of this study lies in the size of the cohort, the use of validated PROMs (Mini-AQLQ and ACT) and the inclusion of clinically well characterized asthmatic patients, but our study has several limitations. As this was a cross-sectional study, the cause and effect of these associations cannot be determined. Another limitation is the lack of socio-demographic data such as the profession or education level which are likely to influence asthma-related quality of life $\left({ }^{3} 8\right)$. Finally, we have not included in our analysis several comorbidities such as rhinosinusitis or gastroesophageal reflux, known to impact quality of life of asthmatics $\left(\begin{array}{ll}3142 & 42\end{array}\right)$.

\section{Conclusion}

Asthma control is the main predictor of asthma quality of life even if some demographic characteristics like gender, BMI and smoking status may also impact certain domains of the quality of life. In addition, FENO emerged as the only inflammatory factor independently associated with AQLQ and the relationship was surprisingly positive between FENO and the activity dimension. Whichever the reason for this, our study shows that taking into account a patient-reported outcome may refine the view of the clinicians on an objective physiological parameter.

DECLARATIONS

\section{Declarations}

\section{Ethics approval and consent to participate}

Study was approved by the $\mathrm{CHU}$ Liège ethics committee. Signed informed consent was obtained from patients as soon as they entered the asthma clinic of the $\mathrm{CHU}$ Liège. They agreed that their clinical data and the health outcomes they reported in the routine setting would be used for the purposes of research.

\section{Consent for publication}

Not applicable.

\section{Competing interests}

Outside of this submitted work, RL received unrestricted research grants from GSK, AstraZeneca, Novartis and Chiesi and lecture or adboard fees from GSK, AZ, Novartis and Sonafi. Outside of this submitted work, FS received lecture or adboard fees from Chiesi, AZ, GSK, and Novartis. The rest of the authors declare that they have no relevant conflicts of interest.

\section{Funding}


The study received support from a federal Grant of Belgian Government (EOS 0013618F) and by the European Regional Development Fund (ERDF) from the "approche patient partenaire de soins" (APPS) project in Grande Région/GroßRégion.

\section{Authors' contributions}

$\mathrm{GL}, \mathrm{BP}, \mathrm{FS}$ and RL contributed to the conception of the study. FS, FG, MH, VP and RL contributed to data acquisition. GL, HNZ, AFD performed statistical analysis. GL, BP, FS, RL, MG and AS drafted and critically revised the work. All authors gave final approval of the manuscript.

\section{Acknowledgements}

Not applicable.

\section{References}

1. GLOBAL STRATEGY FOR ASTHMA MANAGEMENT AND PREVENTION Updated 2020;; 2020. . Accessed August $21,2020$.

2. Weiss KB, Gergen PJ, Hodgson TA. An economic evaluation of asthma in the united states. N Engl J Med. 1992;326(13):862-6. doi:10.1056/NEJM199203263261304.

3. Upton J, Lewis C, Humphreys E, Price D, Walker S. Asthma-specific health-related quality of life of people in Great Britain: A national survey. J Asthma. 2016;53(9):975-82. doi:10.3109/02770903.2016.1166383.

4. Chung JH, Han $\mathrm{CH}$. Health related quality of life in relation to asthma-Data from a cross sectional study. J Asthma. 2018;55(9):1011-7. doi:10.1080/02770903.2017.1387266.

5. Sullivan PW, Smith KL, Ghushchyan VH, Globe DR, Lin SL, Globe G. Asthma in USA: Its impact on health-related quality of life. J Asthma. 2013;50(8):891-9. doi:10.3109/02770903.2013.813035.

6. Schmier JK, Chan KS, Leidy NK. The impact of asthma on health-related quality of life. J Asthma. 1998;35(7):585-97. doi:10.3109/02770909809048961.

7. Katz PP, Yelin EH, Eisner MD, Blanc PD. Perceived control of asthma and quality of life among adults with asthma. Ann Allergy Asthma Immunol. 2002;89(3):251-8. doi:10.1016/S1081-1206(10)61951-5.

8. Chen $\mathrm{H}$, Gould MK, Blanc PD, et al. Asthma control, severity, and quality of life: Quantifying the effect of uncontrolled disease. J Allergy Clin Immunol. 2007;120(2):396-402. doi:10.1016/j.jaci.2007.04.040.

9. Gonzalez-Barcala FJ, De La Fuente-Cid R, Tafalla M, Nuevo J, Caamaño-Isorna F. Factors associated with health-related quality of life in adults with asthma. A cross-sectional study. Multidiscip Respir Med. 2012;7(5). doi:10.1186/2049-6958-7-32.

10. Leander M, Lampa E, Janson C, Svrdsudd K, Uddenfeldt M, Rask-Andersen A. Determinants for a low health-related quality of life in asthmatics. Ups J Med Sci. 2012;117(1):57-66. doi:10.3109/03009734.2011.638730.

11. Oni OA, Erhabor GE, Oluboyo PO. Does health-related quality of life in asthma patients correlate with the clinical indices? South African Fam Pract. 2014;56(2):134-8. doi:10.1080/20786204.2014.10855351.

12. Hesselink AE, van der Windt DAWM, Penninx BWJH, et al. What Predicts Change in Pulmonary Function and Quality of Life in Asthma or COPD? J Asthma. 2006;43(7):513-9. doi:10.1080/02770900600856954.

13. Böhmer MM, Brandl M, Brandstetter S, et al. Factors associated with generic health-related quality of life in adult asthma patients in Germany: Cross-sectional study. J Asthma. 2017;54(3):325-34. doi:10.1080/02770903.2016.1206563.

14. Nathan RA, Sorkness CA, Kosinski M, et al. Development of the Asthma Control Test: A survey for assessing asthma control. J Allergy Clin Immunol. 2004;113(1):59-65. doi:10.1016/j.jaci.2003.09.008.

15. Juniper EF, Guyatt GH, Cox FM, Ferrie PJ, King DR. Development and validation of the Mini Asthma Quality of Life Questionnaire. Eur Respir J. 1999;14(1):32-8. doi:10.1034/j.1399-3003.1999.14a08.x.

16. Anota A, Touraine C, Ousmen A, et al. Méthodes de détermination de la différence minimale cliniquement importante pour les questionnaires de qualité de vie relative à la santé en cancérologie. Rev Epidemiol Sante Publique. 2017;65:66. doi:10.1016/j.respe.2017.03.041.

17. Schatz M, Mosen D, Apter AJ, et al. Relationships among quality of life, severity, and control measures in asthma: An evaluation using factor analysis. J Allergy Clin Immunol. 2005;115(5):1049-55. doi:10.1016/j.jaci.2005.02.008.

18. Demarche SF, Schleich FN, Henket MA, Paulus VA, Van Hees TJ, Louis RE. Effectiveness of inhaled corticosteroids in real life on clinical outcomes, sputum cells and systemic inflammation in asthmatics: A retrospective cohort study in a secondary care centre. BMJ Open. 2017;7(11). doi:10.1136/bmjopen-2017-018186.

19. Smithson M, Verkuilen J. A better lemon squeezer? Maximum-likelihood regression with beta-distributed dependent variables. Psychol Methods. 2006;11(1):54-71. doi:10.1037/1082-989X.11.1.54.

Page 10/16 
20. Pereira EDB, Cavalcante AG, de M, Pereira, Lucas ENS, Holanda P. MA. Asthma control and quality of life in patients with moderate or severe asthma. J Bras Pneumol. 2011;37(6):705-11. doi:10.1590/s1806-37132011000600002.

21. Williams SA, Wagner S, Kannan H, Bolge SC. The association between asthma control and health care utilization, work productivity loss and health-related quality of life. J Occup Environ Med. 2009;51(7):780-5. doi:10.1097/JOM.0b013e3181abb019.

22. Stucky BD, Sherbourne CD, Edelen MO, Eberhart NK. Understanding asthma-specific quality of life: Moving beyond asthma symptoms and severity. Eur Respir J. 2015;46(3):680-7. doi:10.1183/09031936.00225014.

23. de Sousa JC, Pina A, Cruz AM, et al. Asthma control, quality of life, and the role of patient enablement: A cross-sectional observational study. Prim Care Respir J. 2013;22(2):181-7. doi:10.4104/pcrj.2013.00037.

24. Naleway AL, Vollmer WM, Frazier EA, O’Connor E, Magid DJ. Gender Differences in Asthma Management and Quality of Life. J Asthma. 2006;43(7):549-52. doi:10.1080/02770900600858992.

25. Belloch A, Perpiñá M, Martínez-Moragón E, de Diego A, Martínez-Francés M. Gender differences in health-related quality of life among patients with asthma. J Asthma. 2003;40(8):945-53. doi:10.1081/jas-120024595.

26. Wijnhoven HAH, Kriegsman DMW, Snoek FJ, Hesselink AE, De Haan M. Gender differences in health-related quality of life among asthma patients. J Asthma. 2003;40(2):189-99. doi:10.1081/JAS-120017990.

27. Woods SE, Sorscher J, King J, Hasselfeld K. Young Adults Admitted for Asthma: Does Gender Influence Outcomes? Vol 12.; 2003. . Accessed August 20, 2020.

28. Peerboom S, Graff S, Seidel L, et al. Predictors of a good response to inhaled corticosteroids in obesity-associated asthma. Biochem Pharmacol. 2020;179. doi:10.1016/j.bcp.2020.113994.

29. van Bragt JJMH, Adcock IM, Bel EHD, et al. Characteristics and treatment regimens across ERS SHARP severe asthma registries. Eur Respir J. 2020;55(1). doi:10.1183/13993003.01163-2019.

30. Lavoie KL, Bacon SL, Labrecque M, Cartier A, Ditto B. Higher BMI is associated with worse asthma control and quality of life but not asthma severity. Respir Med. 2006;100(4):648-57. doi:10.1016/j.rmed.2005.08.001.

31. Ek A, Middelveld RJM, Bertilsson $\mathrm{H}$, et al. Chronic rhinosinusitis in asthma is a negative predictor of quality of life: results from the Swedish GA 2 LEN survey. Allergy. 2013;68(10):1314-21. doi:10.1111/all.12222.

32. Demarche SF, Schleich FN, Paulus VA, Henket MA, Van Hees TJ, Louis RE. Asthma Control and Sputum Eosinophils: A Longitudinal Study in Daily Practice. J Allergy Clin Immunol Pract. 2017;5(5):1335-43.e5. doi:10.1016/j.jaip.2017.01.026.

33. Schleich FN, Chevremont A, Paulus V, et al. Importance of concomitant local and systemic eosinophilia in uncontrolled asthma. Eur Respir J. 2014;44(1):97-108. doi:10.1183/09031936.00201813.

34. Schleich FN, Seidel L, Sele J, et al. Exhaled nitric oxide thresholds associated with a sputum eosinophil count $\geq 3 \%$ in a cohort of unselected patients with asthma. Thorax. 2010;65(12):1039-44. doi:10.1136/thx.2009.124925.

35. Roberts G, Mylonopoulou M, Hurley C, Lack G. Impairment in quality of life is directly related to the level of allergen exposure and allergic airway inflammation. Clin Exp Allergy. 2005;35(10):1295-300. doi:10.1111/j.1365-2222.2005.02333.x.

36. Caminati M, Vianello A, Chieco Bianchi F, et al. Relevance of TH2 markers in the assessment and therapeutic management of severe allergic asthma: A real-life perspective. J Investig Allergol Clin Immunol. 2020;30(1):35-41. doi:10.18176/jiaci.0379.

37. Moncada S, Higgs EA. The discovery of nitric oxide and its role in vascular biology. Br J Pharmacol. 2006;147(SUPPL. 1). doi:10.1038/sj.bjp.0706458.

38. Ricciardolo FLM, Sterk PJ, Gaston B, Folkerts G. Nitric oxide in health and disease of the respiratory system. Physiol Rev. 2004;84(3):73165. doi:10.1152/physrev.00034.2003.

39. Haldar P, Brightling CE, Hargadon B, et al. Mepolizumab and Exacerbations of Refractory Eosinophilic Asthma. N Engl J Med. 2009;360(10):973-84. doi:10.1056/NEJMoa0808991.

40. Schleich F, Graff S, Nekoee H, et al. Real-world experience with mepolizumab: Does it deliver what it has promised? Clin Exp Allergy. 2020;50(6):687-95. doi:10.1111/cea.13601.

41. Bousquet J, Arnavielhe S, Bedbrook A, et al. The Allergic Rhinitis and its Impact on Asthma (ARIA) score of allergic rhinitis using mobile technology correlates with quality of life: The MASK study. Allergy. 2018;73(2):505-10. doi:10.1111/all.13307.

42. Vandenplas O, Dramaix M, Joos G, et al. The impact of concomitant rhinitis on asthma-related quality of life and asthma control. Allergy Eur J Allergy Clin Immunol. 2010;65(10):1290-7. doi:10.1111/j.1398-9995.2010.02365.x.

\section{Figures}




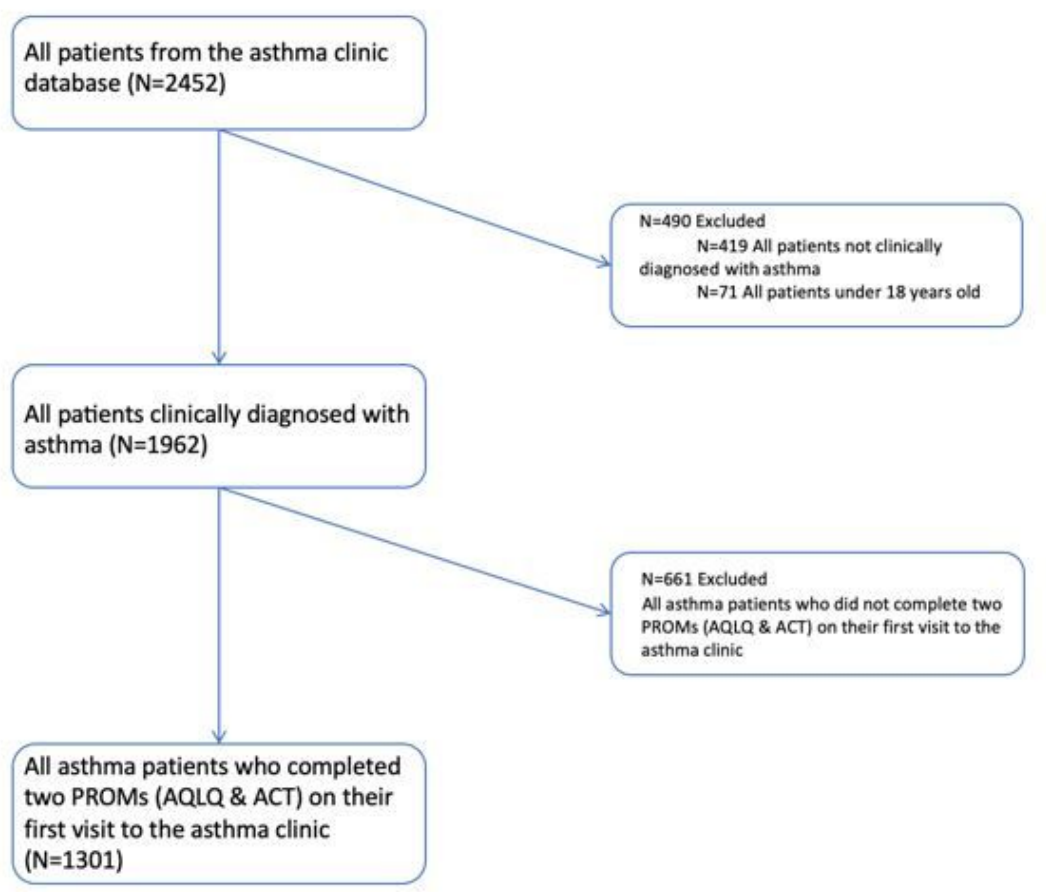

\section{Figure 1}

Flow chart of the patient selection process. PROM is patient-reported outcome measure. AQLQ is asthma quality of life questionnaire. ACT is asthma control test.

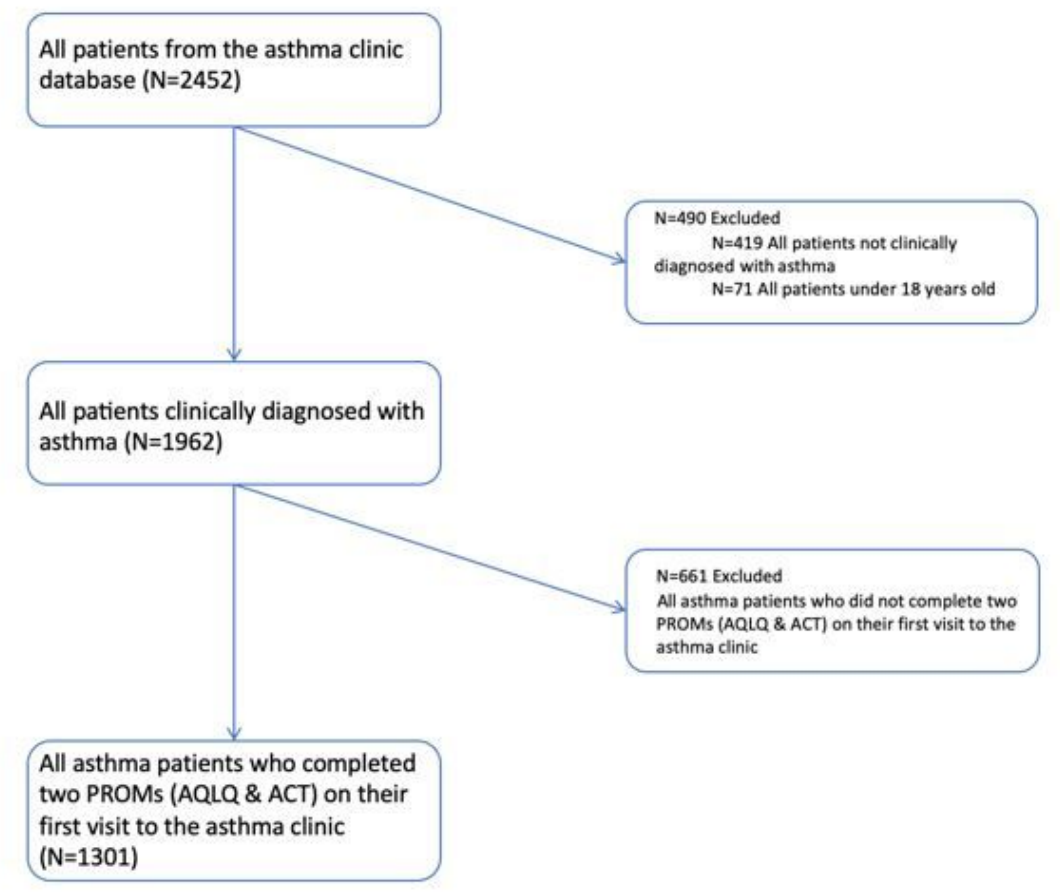

Figure 1 
Flow chart of the patient selection process. PROM is patient-reported outcome measure. AQLQ is asthma quality of life questionnaire. ACT is asthma control test.

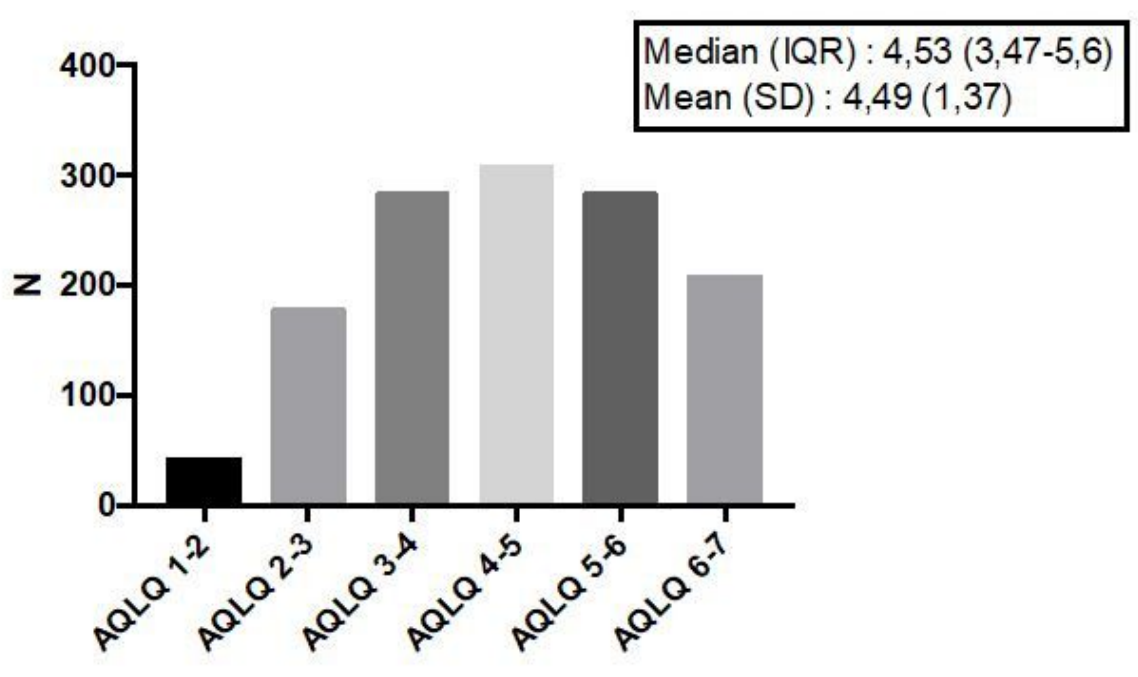

Figure 2

Distribution of the global AQLQ score on the whole cohort $(\mathrm{N}=1301)$. IQR is interquartile range, while SD is standard deviation.

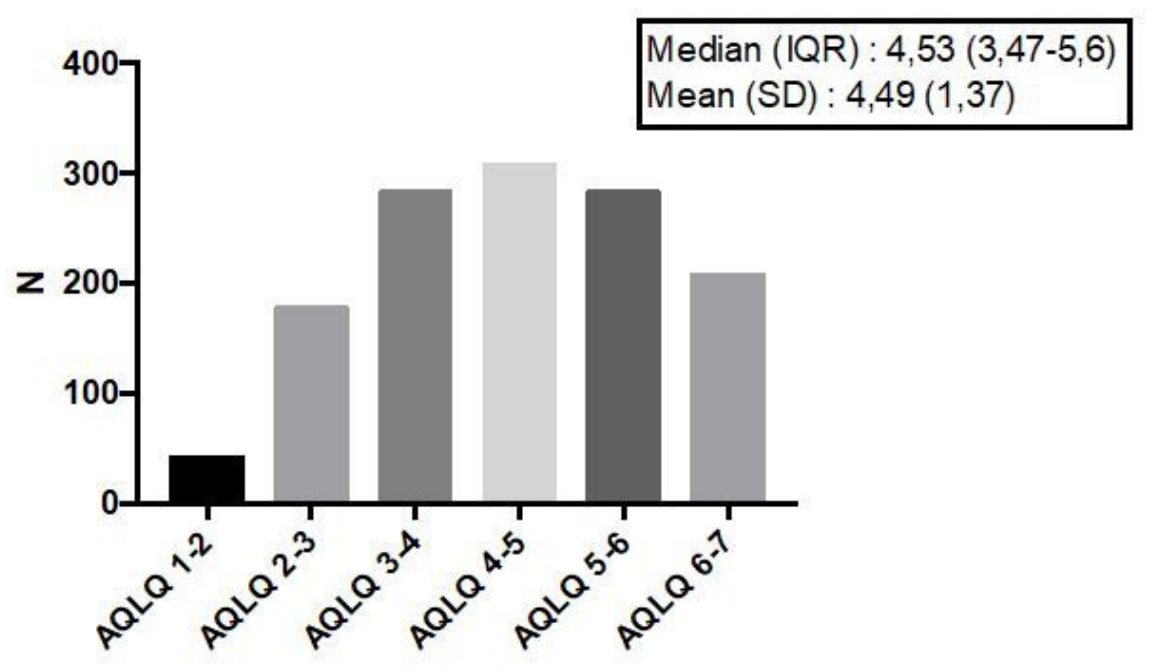

Figure 2

Distribution of the global AQLQ score on the whole cohort $(\mathrm{N}=1301)$. IQR is interquartile range, while SD is standard deviation. 

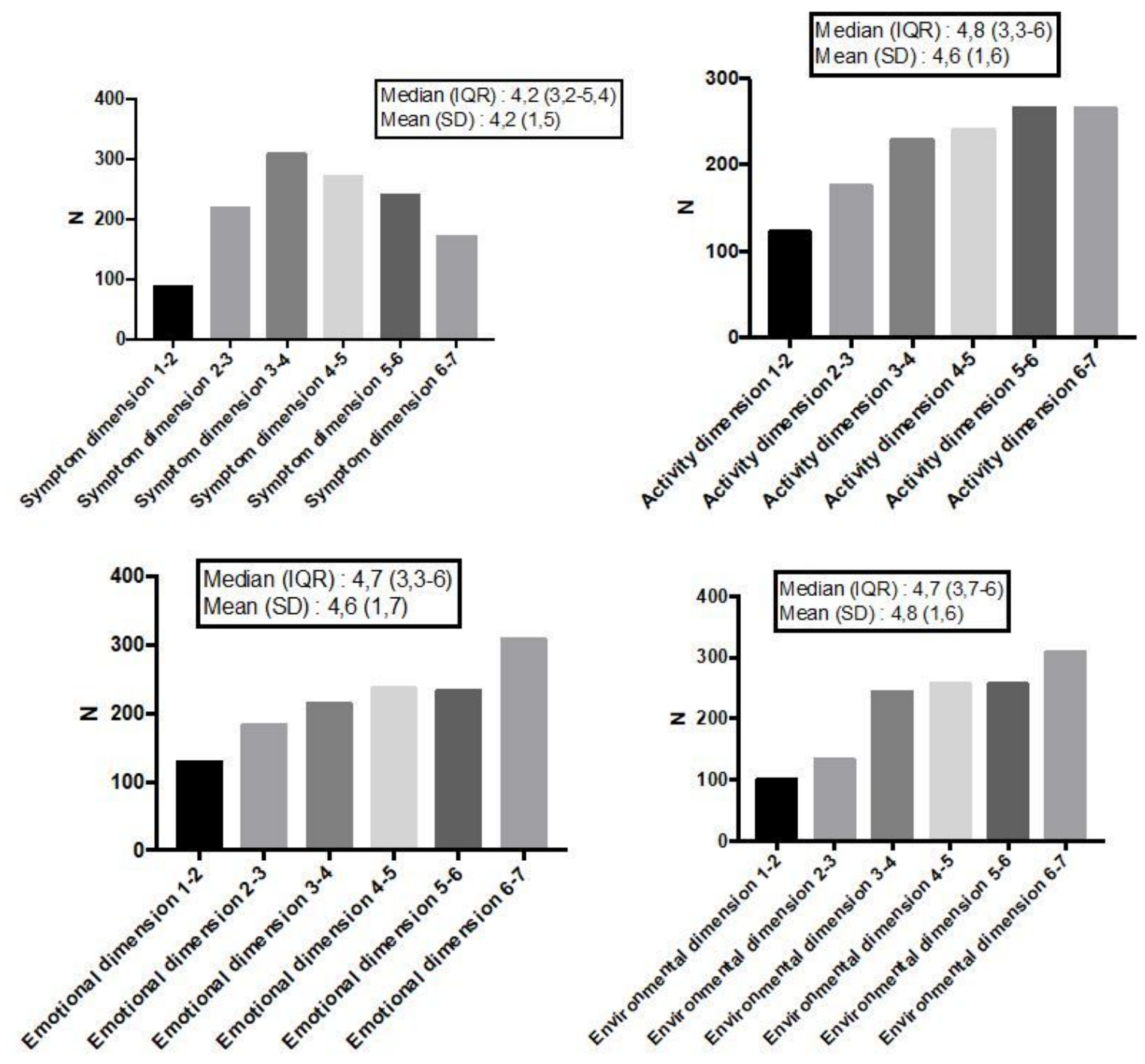

Figure 3

Distribution of the 4 AQLQ dimensions score on the whole cohort $(N=1301)$. IQR is interquartile range, while $S D$ is standard deviation. 


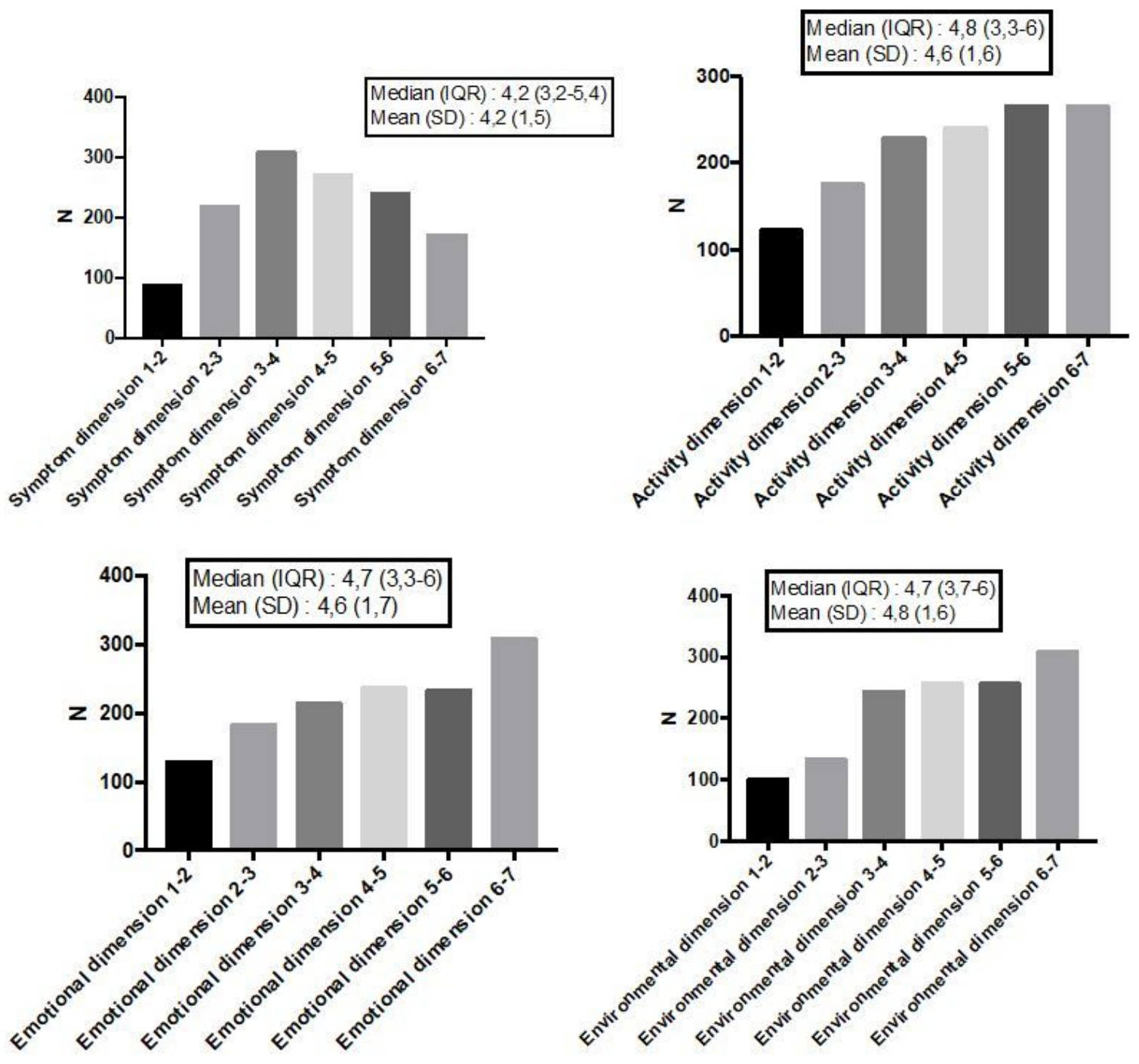

Figure 3

Distribution of the 4 AQLQ dimensions score on the whole cohort $(\mathrm{N}=1301)$. IQR is interquartile range, while SD is standard deviation.

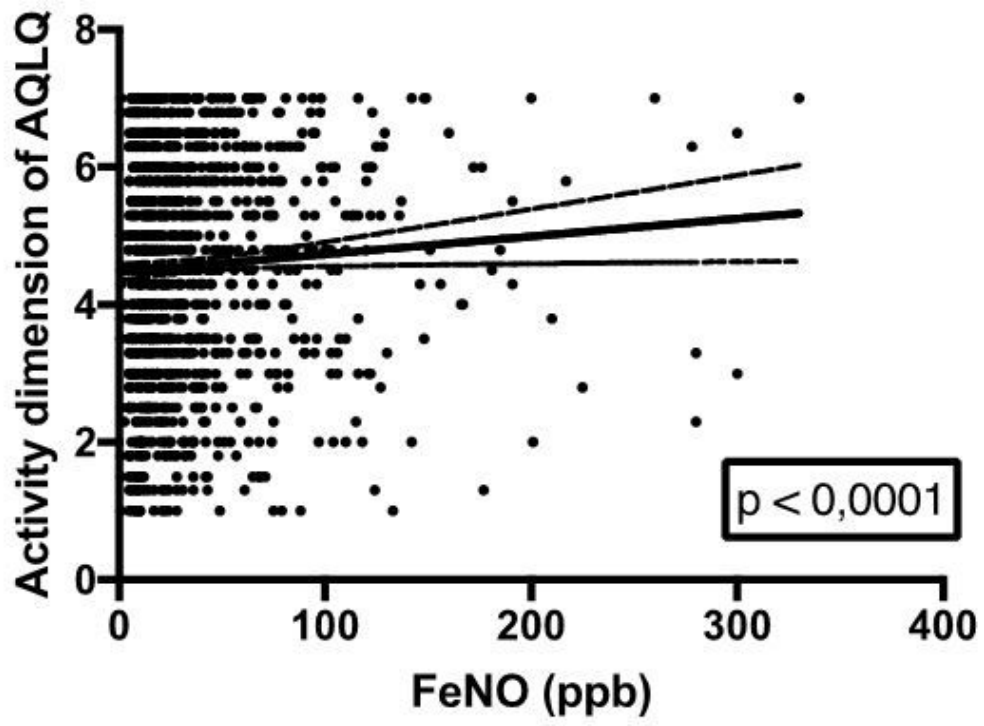


Figure 4

Beta regression between the activity dimension of the AQLQ and FENO (ppb). Solid line is the regression line, while dotted line represents the $95 \%$ interval.

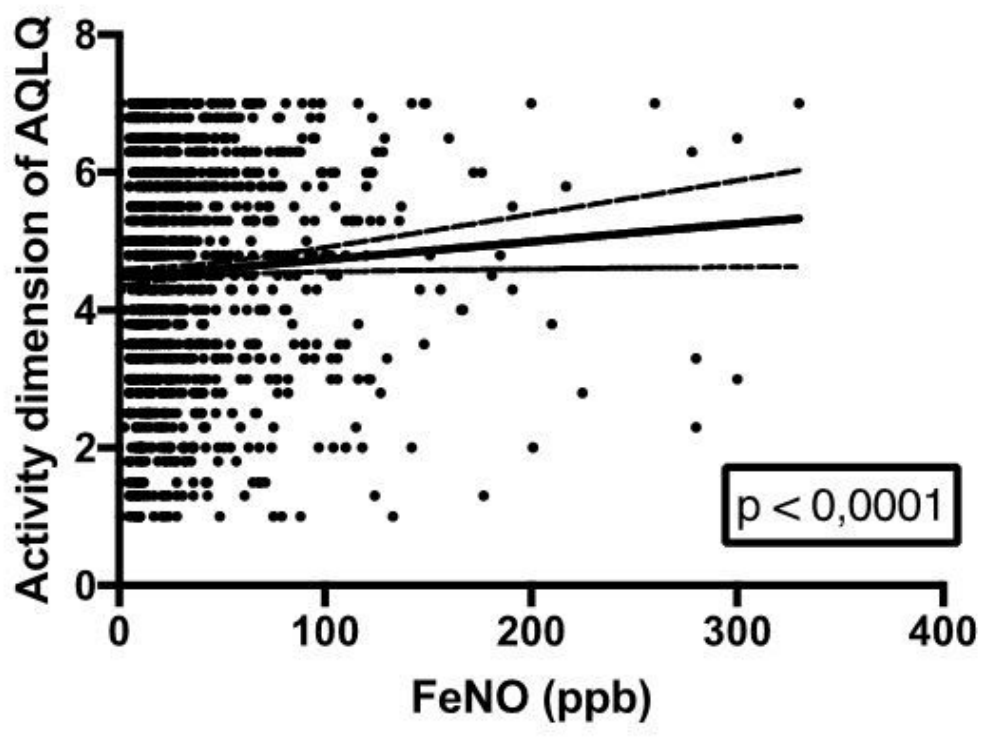

\section{Figure 4}

Beta regression between the activity dimension of the AQLQ and FENO (ppb). Solid line is the regression line, while dotted line represents the $95 \%$ interval. 